\title{
Systemic Lupus Erythematosus-associated Pulmonary Arterial Hypertension: Serial Case Report
}

Yunia Duana, Lucia Kris Dinarti*, Dyah Wulan Anggrahini, Anggoro Budi Hartopo, Bambang Irawan

Department of Cardiology and Vascular Medicine, Faculty of Medicine, Public Health and Nursing, Universitas Gadjah Mada Sardjito General Hospital, Yogyakarta, Indonesia

ARTICLE INFO
*Corresponding author
Email:
kris_dinarti@ugm.ac.id
Address:
Jalan Farmako Sekip Utara, Yogyakarta 55281
Keywords:
connective tissue disease; pulmonary arterial
hypertension; right heart failure; systemic
lupus erythematosus

Manuscript submitted: September 29, 2021

Revised and accepted: December 2, 2021

\section{ABSTRACT}

One of the causes of pulmonary arterial hypertension (PAH) is connective tissue disease, including systemic lupus erythematosus (SLE). The prevalence of PAH in patients with SLE according to cohort studies varies widely between $0.5 \%$ and $43 \%$. In some cases, PAH is the initial manifestation leading to the diagnosis of SLE. However, PAH can develop as a complication in patients who are initially diagnosed with SLE. We report two cases with a different approach to the diagnosis of pulmonary hypertension in SLE patients. These cases emphasize the importance of investigating examination results according to the guidelines to establish the diagnosis of PAH in SLE.

\section{INTISARI}

Salah satu penyebab terjadinya hipertensi arteri pulmonal (HAP) adalah penyakit jaringan ikat termasuk systemic lupus erythematosus (SLE). Penelitian kohort telah melaporkan bahwa prevalensi HAP pada SLE bervariasi antara 0,5\% dan 43\%. Pada beberapa kasus, HAP merupakan manifestasi pertama yang mengarah ke diagnosis SLE. Namun, PAH juga bisa menjadi komplikasi yang terjadi setelah pasien terdiagnosis SLE dalam waktu yang lama. Kami melaporkan dua kasus dengan pendekatan berbeda dalam penegakan diagnosis hipertensi pulmonal pada pasien SLE. Kasus ini menekankan pentingnya melakukan pemeriksaan sesuai hasil pemeriksaan dengan panduan untuk menegakkan diagnosis HAP pada SLE.

\section{Introduction}

Pulmonary hypertension (PH) is defined by a mean pulmonary artery pressure (mPAP) $>20 \mathrm{~mm} \mathrm{Hg}$ at rest, measured during right heart catheterization (1). Pulmonary hypertension is classified into five groups based on pathological findings, hemodynamics characteristics and management. Five groups of disorders that cause $\mathrm{PH}$ were identified: pulmonary arterial hypertension (PAH) (Group 1); PH due to left heart disease (Group 2); PH due to $\mathrm{PH}$ due to unclear multifactorial mechanism (Group 5) (2). Pulmonary arterial hypertension $(\mathrm{PAH})$ describes a group of patients with $\mathrm{PH}$ characterized hemodynamically by the presence of pre-capillary $\mathrm{PH}$, defined by the concomitant presence of $\mathrm{mPAP}>20 \mathrm{mmHg}$, pulmonary artery wedge pressure (PAWP) $\leq 15 \mathrm{mmHg}$, and PVR $>3$ wood unit (WU) in the absence of other cause of pre-capillary $\mathrm{PH}$ such as $\mathrm{PH}$ due to lung disease, СТEPH, or other rare diseases $(1,3)$. Pulmonary arterial hypertension can be idiopathic (Idiopathic PAH), inherited, caused by drugs or toxins, associated with Human Immunodeficiency Virus (HIV) infection, portal hypertension, congenital heart disease and various connective tissue diseases such as systemic sclerosis, systemic lupus erythematosus (SLE), rheumatoid arthritis (RA), or mixed connective tissue disease (MCTD) (4). Systemic Lupus Erythematosus is a connective tissue disease with the second-highest incidence of PAH after systemic sclerosis. Several studies have reported that the prevalence of PAH in SLE varies from $0.5 \%$ to $43 \%$. In some cases, $\mathrm{PH}$ is the first manifestation that leads to the diagnosis of SLE (5). Here, we reported a case series of SLE with $\mathrm{PH}$. The first case was a patient presenting with right heart failure who was later diagnosed with PH and SLE, while the second case was a patient who had been diagnosed with SLE for a long time who later developed $\mathrm{PH}$.

Case

Case 1

Pulmonary Hypertension was suspected in a 41-year-old woman referred to our hospital with chief complaints of shortness of breath, swollen legs and swollen abdomen. These complaints were felt since 9 months ago, and she had been treated several times in several hospitals with the 
initial diagnosis of asthma. However, after several hospitalizations the patient was finally diagnosed with heart failure. Transthoracic echocardiography (TTE) examination performed at the referring hospital showed the right atrium and right ventricle dilatation. The ejection fraction was $61 \%$ with a normal left heart chamber and intact interventricular and interatrial septum. Moderate tricuspid regurgitation with tricuspid valve gradient (TVG) $67 \mathrm{mmHg}$ and mean pulmonary artery pressure (mPAP) 49 $\mathrm{mmHg}$ was also found with a high probability of PH. Based on the results of the TTE examination, the patient was diagnosed with right heart failure with suspected $\mathrm{PH}$ and was referred to our hospital for further examination.

Physical examination revealed a 175/120 mmHg systemic blood pressure with a heart rate of 100 beats per minute on admission. The respiration rate was 24 times per minute with peripheral saturation of $99 \%$. Lung examination was normal. Cardiac examination showed cardiomegaly, and on auscultation, a grade IV/VI systolic ejection murmur was heard best at the left lower sternal border. Abdominal examination showed mild ascites with hepatomegaly. Pitting oedema was also found at the bilateral lower extremity. Electrocardiogram (ECG) examination showed sinus rhythm with right axis deviation, right bundle branch block and right ventricular hypertrophy (Fig.1). Chest Xray disclosed an enlarged cardiac with normal pulmonary vasculature (Fig.2). Initial laboratory tests showed hyperkalemia (K 5,68 mmol/L) and a mild increase of creatinine serum ( $\mathrm{Cr} 1,36 \mathrm{mg} / \mathrm{dL}$ ). Patient also showed high NT pro BNP level that is as follows: $21,262 \mathrm{pg} / \mathrm{ml}(\mathrm{N}<$ $177.6 \mathrm{pg} / \mathrm{ml}$ ). Other laboratory tests were within normal limits. Based on the initial results of these examinations, she was arranged to get several examinations to look for the cause of right heart failure and the suspicion of PH.

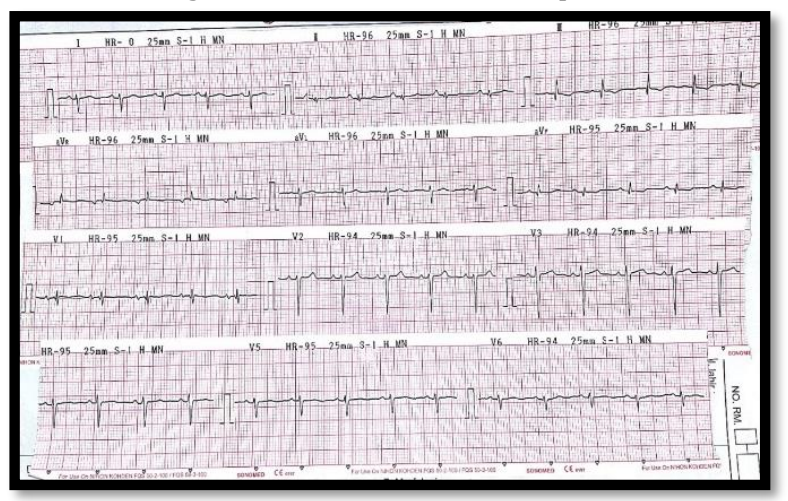

Figure 1. ECG on admission showed sinus rhythm with right axis deviation, right bundle branch block and right ventricular hypertrophy.

The TTE showed dilatation of right atrium and right ventricle with normal dimension and function of the left heart chamber, intact inter ventricular septum, thin inter atrial septum with unclear shunt and moderate tricuspid regurgitation (TVG $75 \mathrm{mmHg}$, tricuspid regurgitation velocity $4,3 \mathrm{~m} / \mathrm{s}$ ) with mild pulmonary regurgitation. The TTE results concluded a high probability of pulmonary hypertension with suspected atrial septal defect (ASD) (Fig.3). Transesophageal echocardiography (TEE) with bubble test to rule out ASD then was conducted and revealed intact atrial septal (Fig. 4). Based on the results of these examinations, she was planned for further examination to look for an extracardiac shunt through thoracic multi slice computed tomography (MSCT) and right heart catheterization (RHC). No extracardiac shunt nor interstitial lung disease was found from MSCT examination. She also underwent a Doppler ultrasonography examination to rule out the possibility of vein thrombus, which was negative.

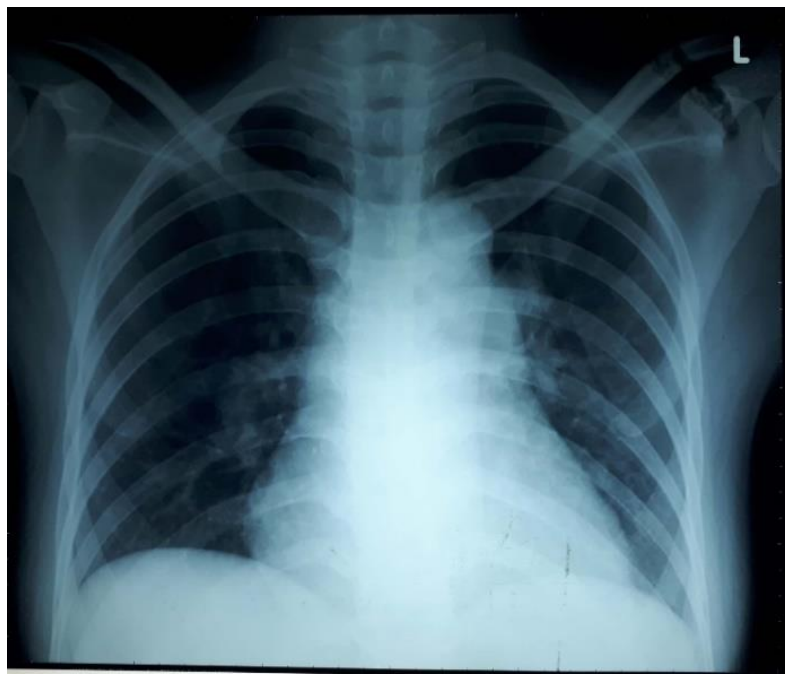

Figure 2. Chest X-ray on admission showed cardiomegaly with normal pulmonary vasculature.

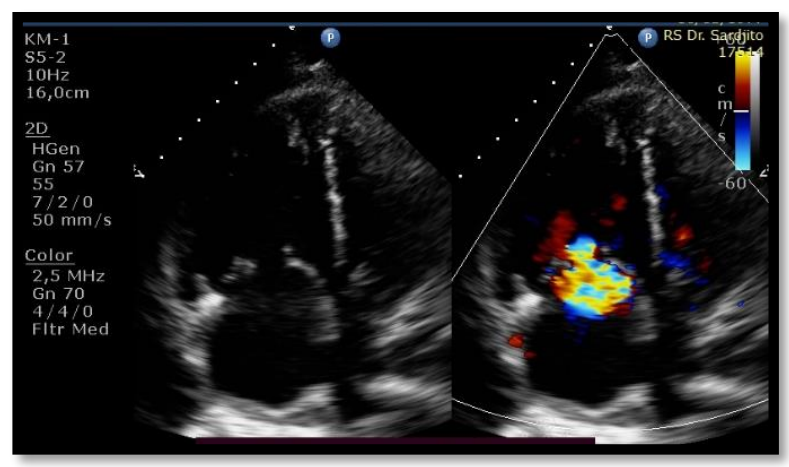

Figure 3. TTE examination showed dilatation of the right atrium and right ventricle with moderate tricuspid regurgitation.

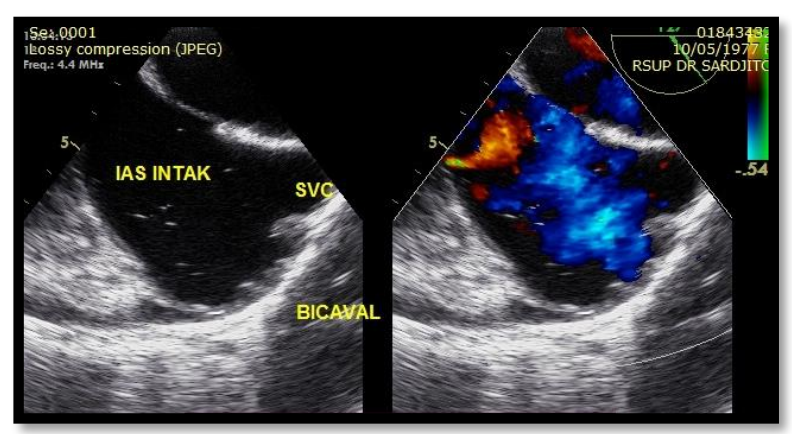


Figure 4. TEE examination in bicaval view showed intact interatrial septum.

Right heart catheterization results were: pulmonary artery pressure 89/42 (61) mmHg, aortic pressure 203/122 (156) $\mathrm{mmHg}$, left ventricle pressure $201 / 7$ (15) $\mathrm{mmHg}$, PVRi 9.56. Left ventricle end diastolic pressure was considered to represent PAWP. No intra and an extracardiac shunt were found. This examination concluded that the patient suffered from severe PAH. Further laboratory examination was then done to found other possible causes of pulmonary hypertension, among others, by checking for anti-nuclear antibodies (ANA), dsDNA, C3, C4. The results were ANA test 1,14 unit (N 2060 unit), anti-ds DNA > $200 \mathrm{U} / \mathrm{mL}(\mathrm{N}<25 \mathrm{U} / \mathrm{ml}), \mathrm{C} 334$ $\mathrm{mg} / \mathrm{dL}$ (N 89-193 mg/dL), C4 4,1 mg/dL (N 10-40 mg/dL). These results support SLE diagnosis with photosensitivity symptoms, ascites, arthritis, and mild renal dysfunction (increased creatinine serum). The patient was then diagnosed with $\mathrm{PH}$ group 1 associated SLE and given therapy for SLE and PAH, consisting of sildenafil $20 \mathrm{mg} / 8$ hours, methyl prednisolone $32 \mathrm{mg}-16 \mathrm{mg}-0$, furosemide 40 $\mathrm{mg} / 24$ hours, and digoxin $0.25 \mathrm{mg} / 24$ hours.

\section{Case 2}

A 49-year-old woman was referred from the internal medicine department in a patient who had an established diagnosis of SLE and anemia hemolytic autoimmune (AIHA) 1 year before. She had a chief complaint of cough, dyspnea on effort, and orthopnea. Physical examination revealed a 100/70 $\mathrm{mmHg}$ systemic blood pressure with a heart rate of 96 beats per minute on admission. The respiration rate was 22 times per minute with peripheral saturation of $99 \%$. Lung examination showed pleural effusion. Cardiac examination showed cardiomegaly, and on auscultation, a grade III/VI pansystolic murmur was heard best at the left lower sternal border. Abdominal examination showed mild ascites with hepatomegaly. Pitting oedema was also found at the bilateral lower extremity. NT-pro BNP result was $1,732 \mathrm{pg} / \mathrm{mL}(\mathrm{N}<177.6$ $\mathrm{pg} / \mathrm{mL}$ ). Electrocardiogram (ECG) examination showed sinus rhythm with normoaxis (Fig. 5). The patient was then diagnosed with heart failure in SLE patient. She underwent a TTE examination to see cardiac function and any structural abnormalities that may be present.

Transthoracic examination showed dilatation of right atrium and right ventricle with normal dimension and function of left heart chamber (ejection fraction 73\%). Moderate tricuspid regurgitation with TVG $49 \mathrm{mmHg}$ and mPAP $54 \mathrm{mmHg}$ was also found with a high probability of pulmonary hypertension. Unfortunately, tricuspid regurgitation velocity as one of the parameters of pulmonary hypertension by TTE had not been used as a standard parameter for determining the probability of $\mathrm{PH}$ at that time. She was also subjected to a thoracic MSCT examination with the results of left inferior pulmonary lobe pneumonia, bilateral pleural effusions, and pulmonary embolism in the bilateral pulmonary arteries, supporting the picture of interstitial lung disease. From these examinations, the patient was diagnosed with right heart failure and pulmonary hypertension in SLE patients with functional class 3 . The patient was given additional therapy with sildenafil $20 \mathrm{mg} / 8$ hours. At that time, the patient was diagnosed with SLE based on TTE results that supported the diagnosis of $\mathrm{PH}$ and it was decided not to do an RHC examination. However, the patient is planned to be evaluated for TTE and NT pro-BNP periodically.
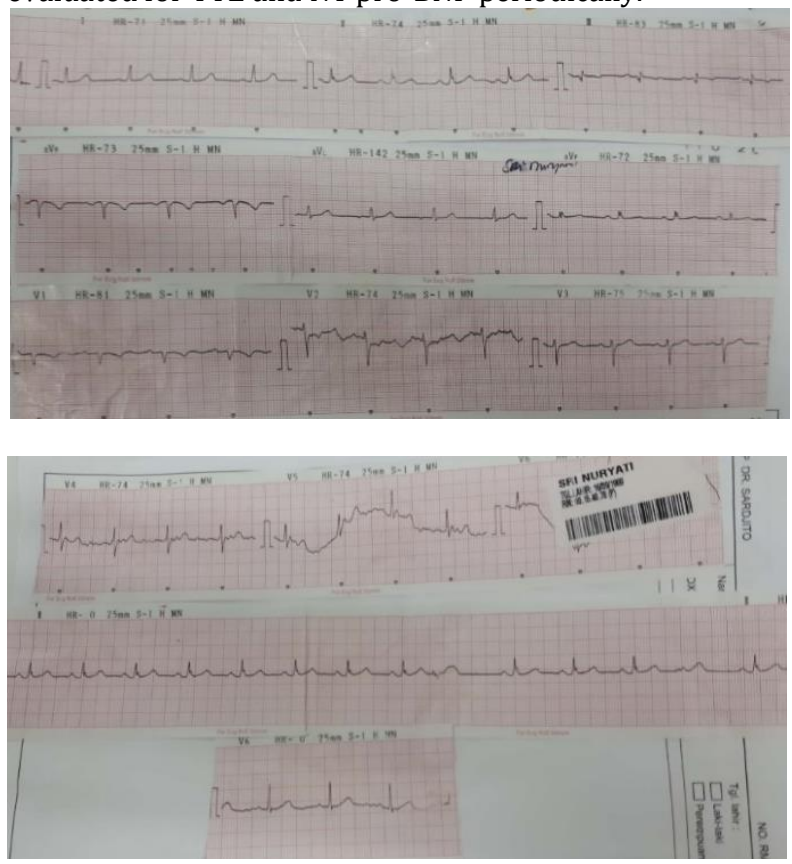

Figure 5. ECG on admission showed sinus rhythm with normoaxis.

Serial TTE evaluation showed improvement in right heart chamber dimensions and tricuspid regurgitation parameters. The initial TTE evaluation (3 months after diagnosis of $\mathrm{PH}$ ) still showed dilatation of the right atrium and right ventricle with moderate tricuspid regurgitation. In contrast, in the third TTE evaluation (1 year after diagnosis of $\mathrm{PH}$ ), the dimensions of the right heart chamber had returned to normal with mild tricuspid regurgitation (Figure 6). Mean pulmonary arterial pressure by TTE was also improved in the third evaluation, where the mPAP decreased from $54 \mathrm{mmHg}$ to $19 \mathrm{mmHg}$. Improvements were also seen in the results of the NT pro BNP evaluation. Initial NT pro-BNP results of $1,732 \mathrm{pg} / \mathrm{mL}$ improved to 55.8 $\mathrm{pg} / \mathrm{mL}$ (1 year later). The patient also experienced an improvement in symptoms. These findings indicated that this patient responded to PAH treatment and supported the diagnosis of $\mathrm{PH}$ group I. 


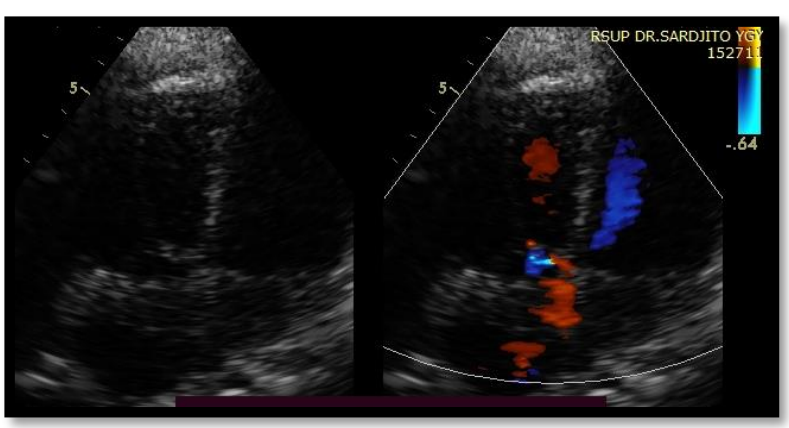

Figure 6. TTE evaluation showed a normal cardiac chamber with mild tricuspid regurgitation.

\section{Discussions}

We reported two cases of PH in SLE patients. The difference between these two cases is that in the first case, the patient was diagnosed with $\mathrm{PH}$, then various tests were done to find the cause of the PH until finally the patient was diagnosed with SLE. Whereas in the second case, the patient had been suffering from SLE for a while, and then the signs and symptoms of PH appeared in the patient. Pulmonary hypertension is a hemodynamic and pathophysiological condition in which there is an increase in the mean pulmonary arterial pressure (PAP) $>20 \mathrm{mmHg}$ when resting through right heart catheterization (RHC) (1). There were five groups of disorders that cause $\mathrm{PH}$ : pulmonary arterial hypertension (PAH) (Group 1); pulmonary hypertension due to left heart disease (Group 2); PH due to chronic lung disease and/or hypoxia (Group 3); chronic thromboembolic PH (CTEPH) (Group 4); and PH due to unclear multifactorial mechanism (Group 5) (2). PAH can be idiopathic (Idiopathic PAH), inherited, caused by drugs or toxins, associated with Human Immunodeficiency Virus (HIV) infection, portal hypertension, congenital heart disease and various connective tissue diseases such as systemic sclerosis, systemic lupus erythematosus (SLE), rheumatoid arthritis (RA), or mixed connective tissue disease (MCTD) (4). Based on the combination of the calculation of PAP, pulmonary arterial wedge pressure (PAWP), cardiac output (CO), diastolic pressure gradient (DPG) and pulmonary vascular resistance (PVR), which are assessed when the condition is stable, the definition of different $\mathrm{PH}$ hemodynamics can be seen in Table 1 and their clinical classifications (1).

Table 1. Hemodynamic definitions of pulmonary

\begin{tabular}{|c|c|c|}
\hline Definitions & Characteristics & Clinical groups \\
\hline Pre-capillary PH & $\begin{array}{c}\mathrm{mPAP}>20 \mathrm{mmHg} \\
\mathrm{PAWP}<15 \mathrm{mmHg} \\
\mathrm{PVR}>3 \mathrm{WU}\end{array}$ & $1,3,4$, and 5 \\
\hline $\begin{array}{l}\text { Isolated post } \\
\text { capillary PH }\end{array}$ & $\begin{array}{c}\mathrm{mPAP}>20 \mathrm{mmHg} \\
\mathrm{PAWP}>15 \mathrm{mmHg} \\
\mathrm{PVR}<3 \mathrm{WU}\end{array}$ & 2 and 5 \\
\hline $\begin{array}{l}\text { Combined pre } \\
\text { and post } \\
\text { capillary PH }\end{array}$ & $\begin{array}{c}\mathrm{mPAP}>20 \mathrm{mmHg} \\
\mathrm{PAWP}>15 \mathrm{mmHg} \\
\mathrm{PVR}>3 \mathrm{WU}\end{array}$ & 2 and 5 \\
\hline
\end{tabular}

Symptoms that occur frequently in $\mathrm{PH}$ are shortness of breath during activity, dry cough, chest pain, and fatigue accompanied by signs of right heart failure such as oedema of the lower limbs and abdominal distension. Tricuspid valve murmur on auscultation can be found with accentuated $\mathrm{P} 2$, and these signs and symptoms were present in both cases $(5,6)$. A physical examination can give sufficient information to diagnose $\mathrm{PH}$ and its severity, but further investigations are still needed to make a more accurate PH diagnosis.

The gold standard for PH diagnosis is RHC, which precisely assesses PAP, PCWP, PVR, and cardiac output. Diagnosis of $\mathrm{PH}$ requires a mean $\mathrm{PAP}>20 \mathrm{mmHg}$ at rest. Documentation of all these parameters can also be used as a tool to determine the etiology of $\mathrm{PH}$ (5). In these cases, the first patient underwent RHC examination to establish the diagnosis of $\mathrm{PH}$ and look for possible causes of $\mathrm{PH}$. Whereas in the second patient, RHC examination was not done considering that the patient had been diagnosed with SLE so that signs of $\mathrm{PH}$ were sought through the TTE examination. The RHC results in the first patient support the diagnosis of pre-capillary $\mathrm{PH}$. According to table 1, precapillary PH differential diagnosis is PH groups 1,3,4 and 5. In this patient, congenital heart disease as the cause of $\mathrm{PH}$ was ruled out by cardiac examination, TTE, TEE, and RHC. Lung disease as the cause of PH group 3 was also ruled out through chest X-ray examination and chest MSCT.

To establish the diagnosis of PH group 4, the gold standard examination that should be done is a ventilation-perfusion scan $(3,5)$. However, this examination was not available in our hospital, so as the alternative, this patient underwent a Doppler ultrasound examination to rule out venous thrombus as the source of pulmonary thrombus and a thoracic MSCT to rule out pulmonary artery thrombus. Laboratory examination was also performed to find the possibility of connective tissue disease-related to PH. After going through various examinations, this patient was finally diagnosed with PAH related to SLE. The diagnostic steps done in this patient are following the $\mathrm{PH}$ diagnosis algorithm in the 2015 ESC for diagnosing and treating pulmonary hypertension (3). In this algorithm, the diagnostic limit for PH still uses mPAP $>25 \mathrm{mmHg}$.

The second patient had been diagnosed with SLE when the patient presented with symptoms of RHF. Accordingly, the approach to diagnosis in this patient was different from the first patient. As previously mentioned, RHC is the gold standard in diagnosing PAH, but RHC is not always feasible due to availability and/or procedure-related complications (mild-to-moderate in $1.1 \%$, mortality $0.055 \%$ ). A TTE can provide a reliable estimation of the RVSP from tricuspid valve regurgitation. On TTE, we also found right atrium and right ventricular dilatation. Some studies showed that the correlation between TTE and RHC was satisfactory, at least for the initial evaluation of such a patient. In general, TTE is recommended for the initial screening of patients with suspected $\mathrm{PAH}$ and the evaluation of response to treatment $(5,7)$. 
Both cases had TTE results that support the high probability of $\mathrm{PH}$. In the first patient, because the cause of $\mathrm{PH}$ was unknown, the patient underwent various examinations to find the cause of $\mathrm{PH}$ and determine the appropriate therapy. The second patient should also undergo RHC examination as the gold standard of diagnosis. Due to limitations and concerns about complications that could occur and because the patient was already diagnosed with SLE, the patient was diagnosed with PH related SLE according to the results of TTE examination and given PAH therapy. The TTE was also used in this patient as a tool to evaluate the response of treatment. The results of the echo evaluation of this patient showed that the patient was responding to therapy. This finding can support the diagnosis of PH group I in this patient.

\section{Conclusions}

In patients with $\mathrm{PH}$, connective tissue disease such as SLE can be considered as one of the etiologies, especially in a female patient. In some cases, $\mathrm{PH}$ may be the first manifestation of SLE. On the contrary, we also must consider $\mathrm{PAH}$ as one of the cardiac complications that patients with SLE can suffer. We can use a different approach to diagnose patients with PH related SLE. These cases emphasize the importance of selecting the most appropriate modality to establish the diagnosis of PAH in SLE.

\section{Acknowlegments}

In patients This case report has been presented in Jogja Cardiology Update 2018, and the abstract has been published on Supplement Abstract of Jogja Cardiology Update (JCU 2018) Vol 4 No 2 (S), (2018).

\section{References}

1. Simonneau G, Montani D, Celermajer DS, Denton CP, Gatzoulis MA, Krowka M, et al. Haemodynamic definitions and updated clinical classification of pulmonary hypertension. Eur Respir J [Internet]. 2019;53(1).

2. Simonneau G, Gatzoulis MA, Adatia I, Celermajer D, Denton C, Ghofrani A, et al. Updated clinical classification of pulmonary hypertension. J Am Coll Cardiol. 2013;62(25 SUPPL.).

3. Galiè N, Humbert $M$, Vachiery JL, Gibbs S, Lang I, Torbicki A, et al. 2015 ESC/ERS Guidelines for the diagnosis and treatment of pulmonary hypertension. Eur Heart J. 2016;37(1):67-119.

4. McLaughlin V V., Shah SJ, Souza R, Humbert M. Management of pulmonary arterial hypertension. J Am Coll Cardiol. 2015;65(18):1976-97.

5. Tselios K, Gladman DD, Urowitz MB. Systemic lupus erythematosus and pulmonary arterial hypertension: Links, risks, and management strategies. Open Access Rheumatol Res Rev. 2017;9:1-9.

6. Rich JD, Rich S. Clinical diagnosis of pulmonary hypertension. Circulation. 2014;130(20):1820-30.

7. Dhala A. Pulmonary arterial hypertension in systemic lupus erythematosus: Current status and future direction. Clin Dev Immunol. 2012;2012. 